\title{
Strategies to avert preventable mortality among mothers and children in the Eastern Mediterranean Region: new initiatives, new hope
}

\author{
N. Akseer, ${ }^{7}$ M. Kamali, ${ }^{7}$ S. Husain, ${ }^{7}$ M. Mirza, ${ }^{7}$ N. Bakhache ${ }^{7}$ and Z.A. Bhutta ${ }^{1,2}$
}

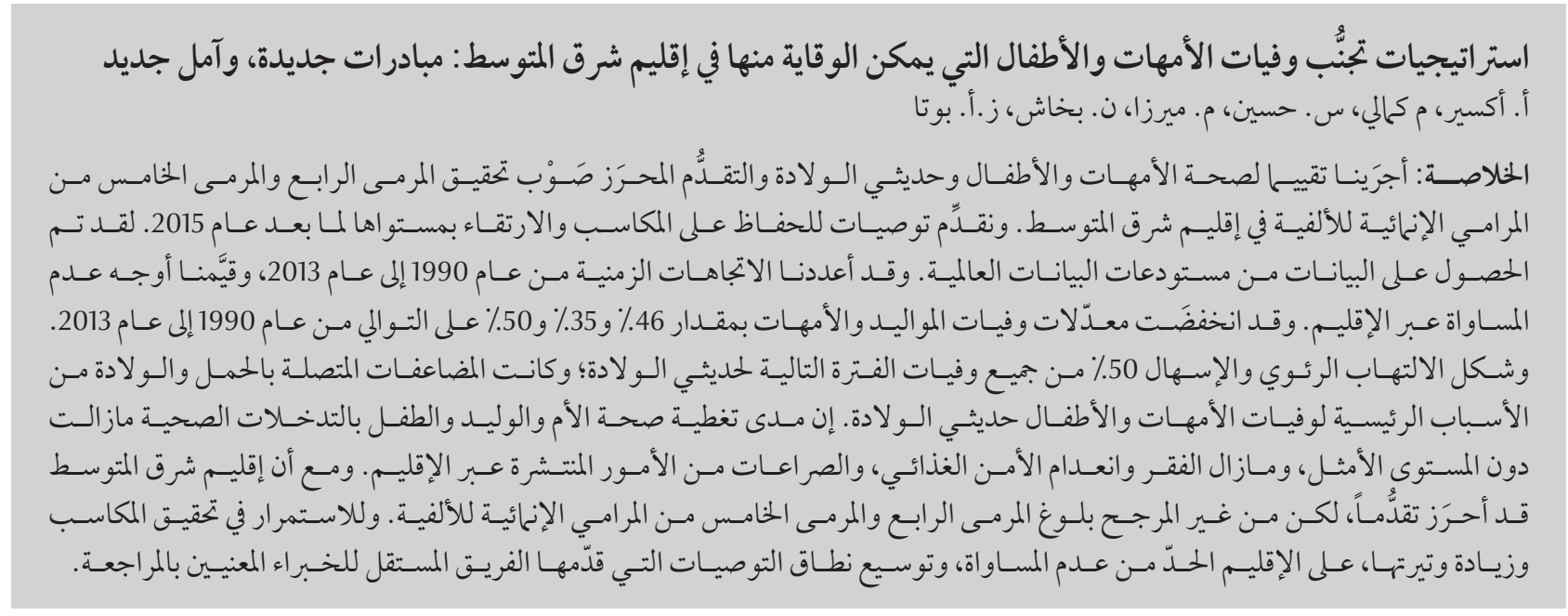

ABSTRACT We conducted an assessment of maternal, newborn and child health and progress towards achieving Millennium Development Goals (MDG) 4 and 5 in the Eastern Mediterranean Region (EMR). We provide recommendations for scaling up and sustaining gains post-2015. Data were obtained from global data repositories. We constructed time trends from 1990 to 2013 and evaluated inequities across the Region. Under-5, neonatal and maternal mortality rates decreased 46\%, 35\%, and 50\% respectively from 1990 to 2013. Pneumonia and diarrhoea accounted for $50 \%$ of all post-neonatal deaths; pregnancy- and delivery-related complications were the leading causes of neonatal and maternal deaths. Coverage of maternal, newborn and child health interventions is suboptimal, and poverty, food insecurity and conflict are pervasive across the Region. The EMR has made progress but is unlikely to attain MDG 4 and 5 targets. To sustain and further accelerate gains, the Region must reduce inequities and scale up implementation of recommendations made by the independent Expert Review Group.

\section{Stratégies permettant de prévenir la mortalité évitable chez les mères et les enfants dans la Région de la Méditerranée orientale : nouvelles initiatives, nouvel espoir}

RÉSUMÉ Nous avons mené une évaluation de la santé de la mère, du nouveau-né et de l'enfant et des progrès effectués sur la voie de la réalisation des objectifs du Millénaire pour le développement (OMD) 4 et 5 dans la Région de la Méditerranée orientale. Nous fournissons des recommandations afin de renforcer et de prolonger les acquis pour la période de l'après-2015. Les données ont été obtenues des systèmes mondiaux d'archivage de données. Nous avons établi des tendances temporelles pour la période allant de 1990 à 2013 et avons évalué les inégalités dans l'ensemble de la Région. Les taux de mortalité des enfants de moins de cinq ans, des nourrissons et des mères ont diminué respectivement de $46 \%$, $35 \%$ et $50 \%$ de 1990 à 2013. La pneumonie et la diarrhée représentaient $50 \%$ de tous les décès post-néonatals ; les complications associées à la grossesse et l'accouchement constituaient les principales causes de décès néonatals et maternels. La couverture des interventions de santé maternelle, néonatale et infantile est sous-optimale, et la pauvreté, l'insécurité alimentaire et les conflits sont très répandus dans l'ensemble de la Région. La Région de la Méditerranée orientale a fait des progrès mais ne devrait probablement pas atteindre les cibles des OMD 4 et 5. Pour pérenniser et accélérer davantage les acquis obtenus, la Région doit réduire les inégalités et intensifier la mise en œuvre des recommandations effectuées par le Groupe d'examen composé d'experts indépendants. 


\section{Introduction}

It has been almost 15 years since the United Nations summit convened to build a roadmap for global policies related to the needs of developing countries (1). The Millennium Development Goals (MDGs) encompassed 8 goals focused primarily on eradicating poverty, achieving universal primary education, environmental sustainability, promoting gender equality, fighting diseases and developing global partnerships (2).

Improving maternal and child health and survival was at the forefront of the agenda, and MDGs 4 and 5 were specifically prioritized to reduce mortality rates in children under 5 years old by two-thirds and maternal mortality rates by threequarters respectively from 1990 base figures, by 2015. With only a few months remaining, remarkableglobal progress has been made in a little over a decade. Globally, the number of under- 5 deaths have declined by approximately 50\% (from 12.7 million to 6.3 million from 1990 to 2013 ) $(3,4)$ and the number of maternal deaths has dropped from 523000 to 289000 (45\% reduction) (5). These gains, however, fall short of meeting the MDG targets, and achievements vary dramatically across regions and nations (6).

The World Health Organization (WHO) Eastern Mediterranean Region (EMR) comprises 22 diverse nations which collectively account for almost $15 \%$ of the total global burden of newborn and child mortality (7). Over the last few decades, the EMR has shown a nearly 12 -year increase in life expectancy; immunization coverage has increased to more than $85 \%$ and the prevalence of communicable disease has dropped substantially (8). However, progress is localized to select countries, and pervasive inequities have contributed to variable success in attaining MDGs 4 and 5 in the Region $(6,9,10)$. As the end of the MDG period quickly approaches and as global efforts transition to the post-2015 Sustainable Development Goals, the EMR must hasten to accelerate gains by reducing inequities and addressing key bottlenecks.

We conducted an updated analysis of maternal, newborn and child health $(\mathrm{MNCH})$ and survival in the EMR, and reviewed recommendations and the way forward for scaling up and maintaining $\mathrm{MNCH}$ successes post-2015.

\section{Methods}

For this review, national estimates of neonatal mortality rates (NMR) and under-5 mortality rates (U5MR) for EMR countries were obtained from the United Nations Inter-agency for Mortality Estimation Group (3), and national estimates of maternal mortality ratios (MMRs) were obtained from the Maternal Mortality Estimation Inter-agency Group (5) serially from 1990 to 2013 inclusive. The annual rate of reduction in U5MR and MMR was used to track progress in achieving MDGs 4 and 5 respectively. We also examined NMR as a component of U5MR, as the issue of neonatal deaths were virtually missing from the MDGs.

It has been estimated that an annual rate of reduction in U5MR of around $4.4 \%$ should be sufficient to achieve MDG 4 targets (3). We classified the Region and countries as: having met the MDG goal if they were currently at or exceeded the MDG 4 target level; as being ontrack if the annual rate of reduction was $\geq 4.0 \%$; as making progress but unlikely to reach the MDG target if the reduction was $2.6-3.9 \%$; and as off-track if the reduction was $\leq 2.5 \%$. Countries with an U5MR $<25$ per 1000 live births in 1990 were not categorized.
Similarly, to attain MDG 5 targets, the global decline in MMR should exceed a minimum of $5.5 \%$ (5). We classified the Region and countries as: having met the MDG 5 goal if they were currently at or exceeded the MDG target level; as on-track if the annual rate of reduction was $\geq$ $5.0 \%$; as making progress but unlikely to reach the MDG target if the reduction was $2.5-4.9 \%$; and off-track if the reduction was $<2.5 \%$. Countries with an MMR < 40 per 100000 live births in 1990 were not categorized.

The Child Health Epidemiology Reference Group (7) and the Institute for Health Metrics and Evaluation (4) provided child and maternal cause of death data for each nation in the EMR for 2013. We pooled causespecific deaths across all countries and calculated the proportion due to each cause for neonates (aged $<1$ month), post-neonates (aged 1-59 months) and mothers.

National estimates for maternal and child health interventions across the continuum of care were obtained from the WHO Global Health Observatory database (11), World Bank (12), United Nations Children's Fund (UNICEF) (13), representative national demographic and health surveys, multiple indicator cluster surveys, and other nationallyrepresentative household surveys. The essential interventions examined included indicators of family planning, immunization, health-care service utilization, illness- and careseeking behaviour, improved water and sanitation facilities (14), and neonatal and child nutrition, including stunting, wasting and overweight (15). The most recent available estimate in the 2000 to 2013 time period was used, and regional medians were calculated. Social determinants, including data on poverty, food insecurity, battle-related deaths, internally-displaced populations, age at marriage and female literacy, were 
also obtained for the most recent year available.

To explore within-Region equity, trends were disaggregated by World Bank income groups (16), and into high-burden and non-high-burden (other) EMR countries. EMR highburden countries include Afghanistan, Djibouti, Egypt, Morocco, Pakistan, Somalia, Sudan and Yemen (17). We also contrasted our analysis with the global trends and with data from developed and developing country regions.

\section{Results}

\section{Child mortality rates}

From the years 1990 to 2013 U5MR in the EMR declined from 101 to 55 deaths per 1000 live births, a 46\% reduction (Figure 1). While progress has been made, the annual rate of reduction of $2.6 \%$ forecasts that the Region will fall short of meeting the MDG 4 target (U5MR of 34 per 1000). U5MR trends are consistently higher in the EMR when compared with global averages, and are on a par with developing countries (Figure 1).

Of the countries in the Region with U5MR > 25 deaths per 1000 live births in 1990, 5 countries reduced U5MR by at least $70 \%$ and have already achieved their MDG 4 targets (Egypt, Islamic Republic of Iran, Tunisia, Oman and Lebanon) (Figure 2). Four countries are on-track (Syrian Arab Republic, Morocco, Saudi Arabia and Libya), while 4 more are making progress but are unlikely to reach their MDG targets (Yemen, Palestine, Jordan and Afghanistan). Five nations are off-track, namely Djibouti, Sudan, Pakistan, Iraq and Somalia (Figure 2). High-income countries, including Bahrain, Qatar, United Arab Emirates and Kuwait, have also reduced U5MR from base values and currently have rates $<10$ per 1000 .

Seven countries accounted for more than $90 \%$ of the 848072 deaths in under 5-year-olds in the Region in 2013 (Somalia, Afghanistan, Pakistan, Sudan, Yemen, Iraq and Egypt) (3). The highest burden countries included Afghanistan, Pakistan and Sudan, which have U5MR among the highest worldwide (3).

More than $45 \%$ of all under- 5 deaths in 2013 occurred within the first month of birth (3). NMR in the Region have declined much slower than U5MR (approximately 35\% reduction) and progress is similar to global and developing regional trends. Afghanistan, Pakistan, Somalia, Sudan and Djibouti made the least progress in reducing NMR between 1990 and 2013 (<35\%) and continue to have rates exceeding 30 newborn deaths per 1000 live births (3).

The major causes of child deaths are pneumonia and diarrhoea, together accounting for approximately $50 \%$ of post-neonatal mortality in the high-burden countries, and $40 \%$ in other EMR countries in 2013 (Figure 3a). Pre-term birth complications and intrapartum-related events represented about one-third and one-fifth respectively of all neonatal deaths in the Region in 2013 (Figure 3b). Newborn death from congenital abnormalities was higher in high-burden

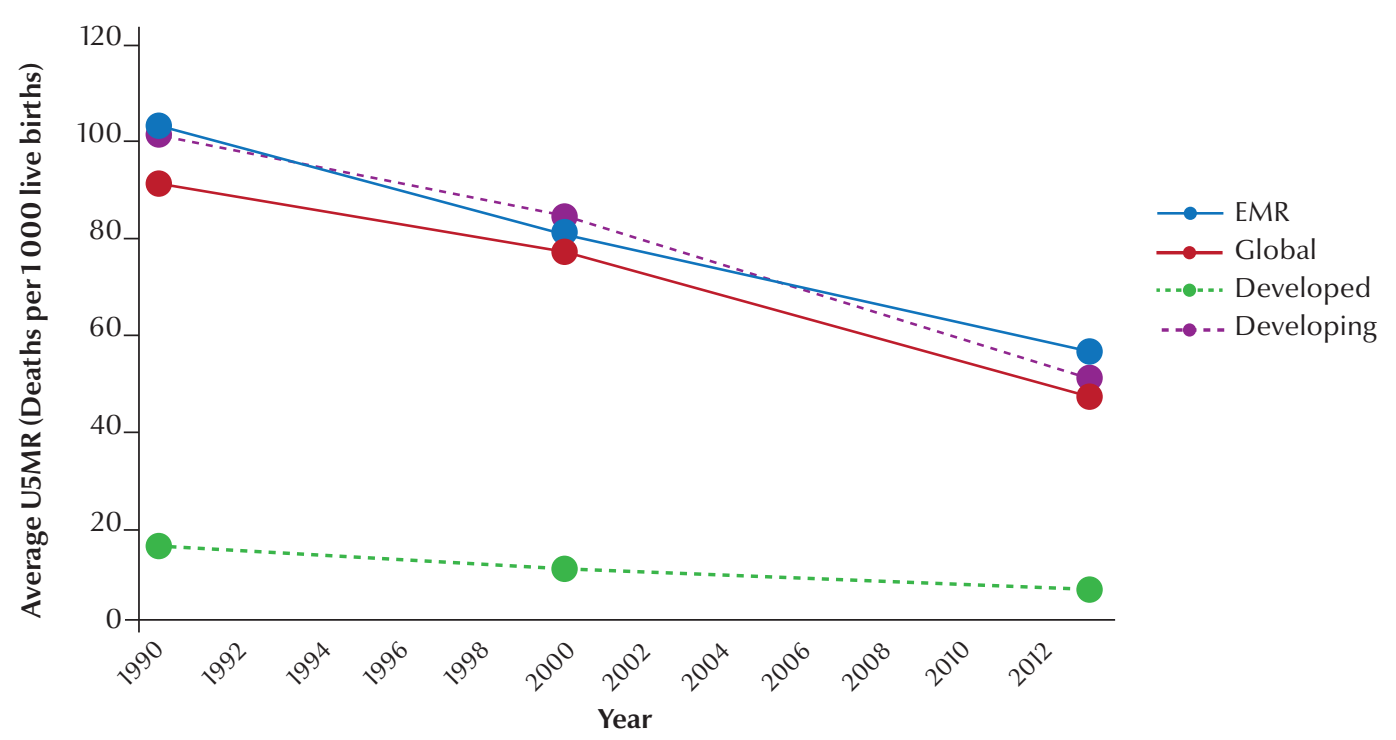

Figure 1 Under-5 mortality rates (U5MR) per 1000 live births from 1990 to 2013 in the Eastern Mediterranean Region, globally and in global developing and developed countries. Source: United Nations Inter-agency Group for Mortality Estimation, $2014(3)$ 


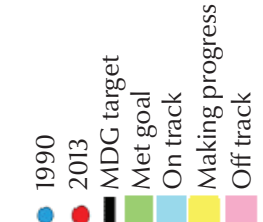
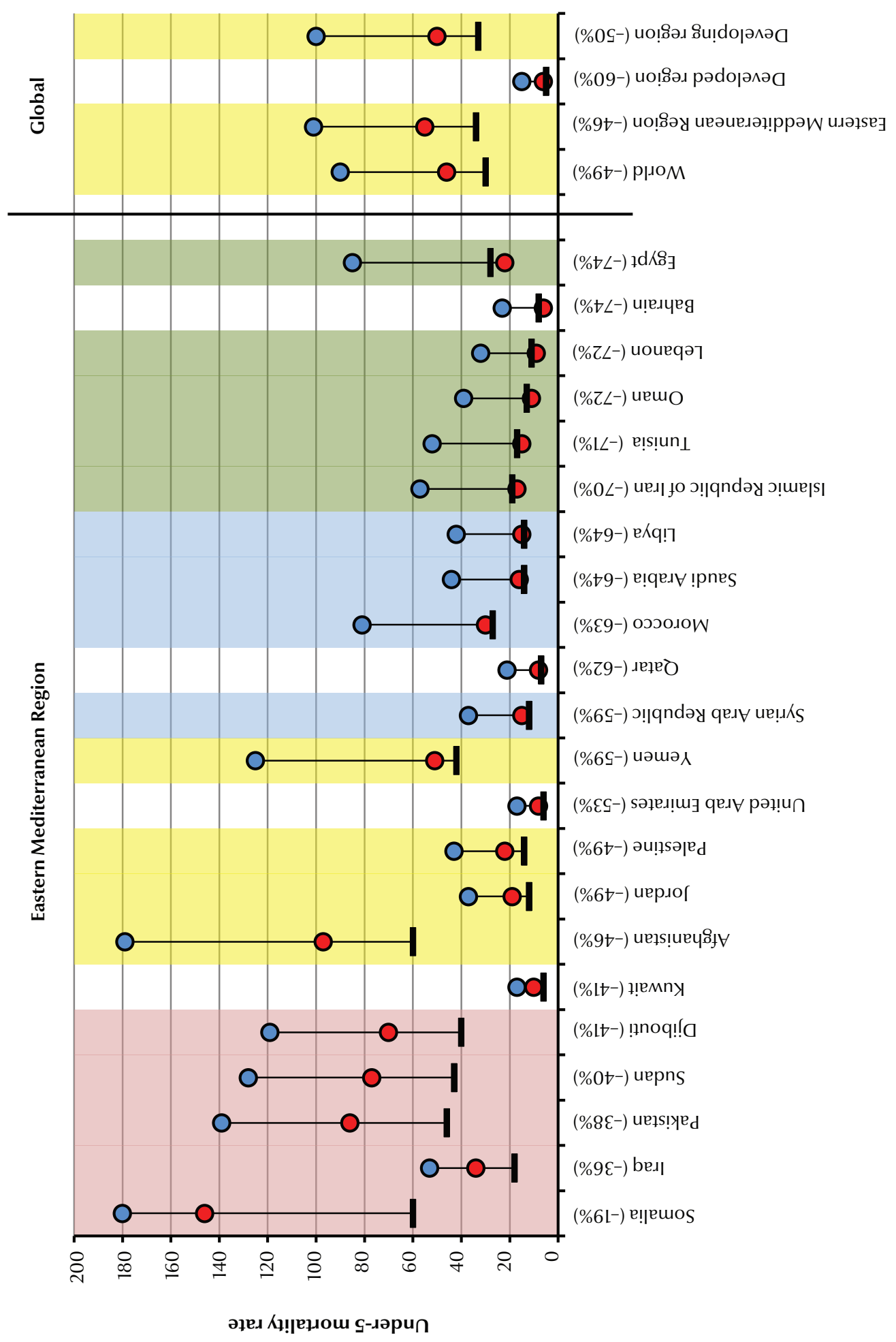


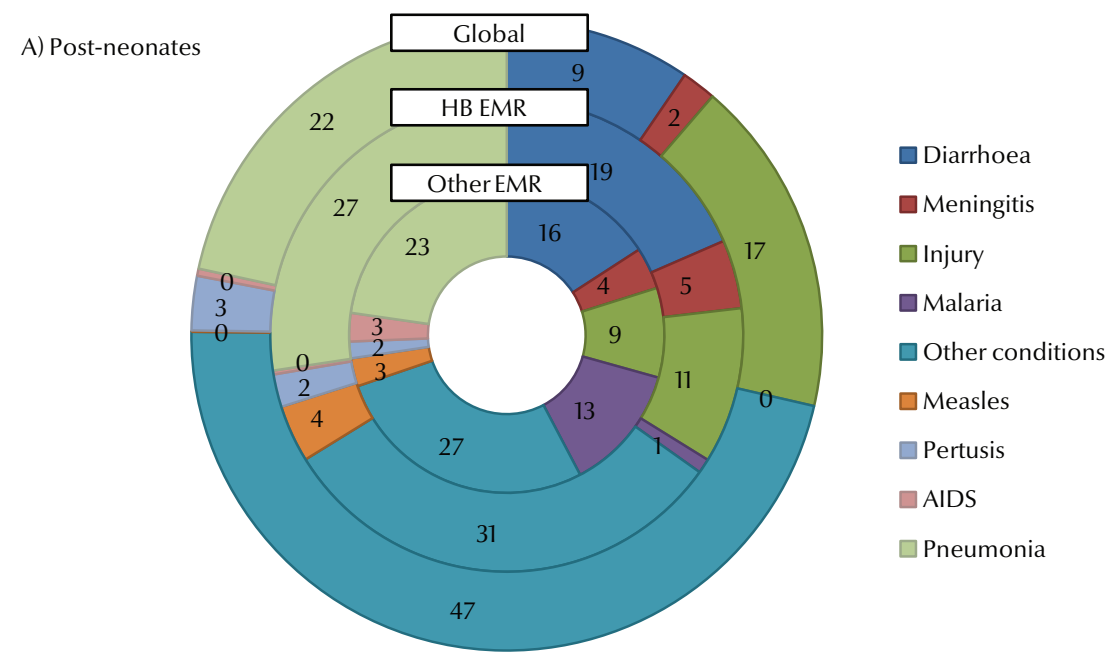

B) Neonates

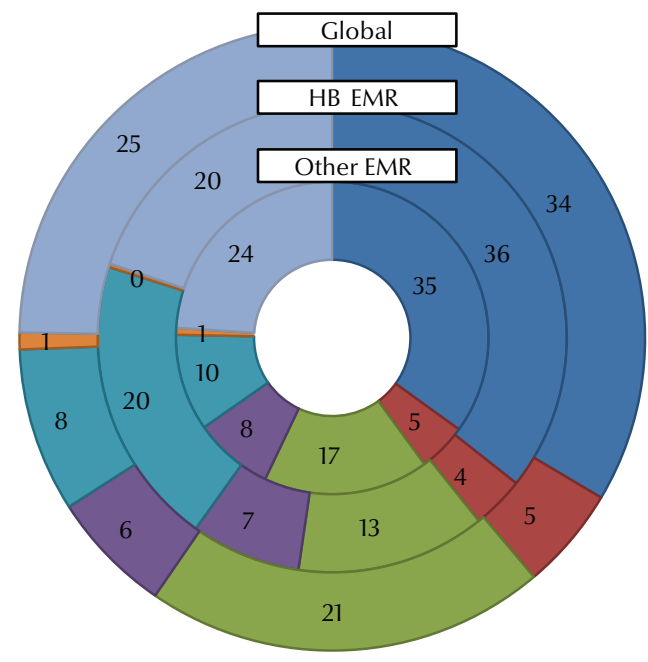

$\square$ Preterm birth complications

$\square$ Pneumonia

$\square$ Sepsis/Meningitis/Tetanus

$\square$ Other conditions

$\square$ Congenital abnormalities

$\square$ Diarrhoea

$\square$ Intrapartum-related events

C) Maternal

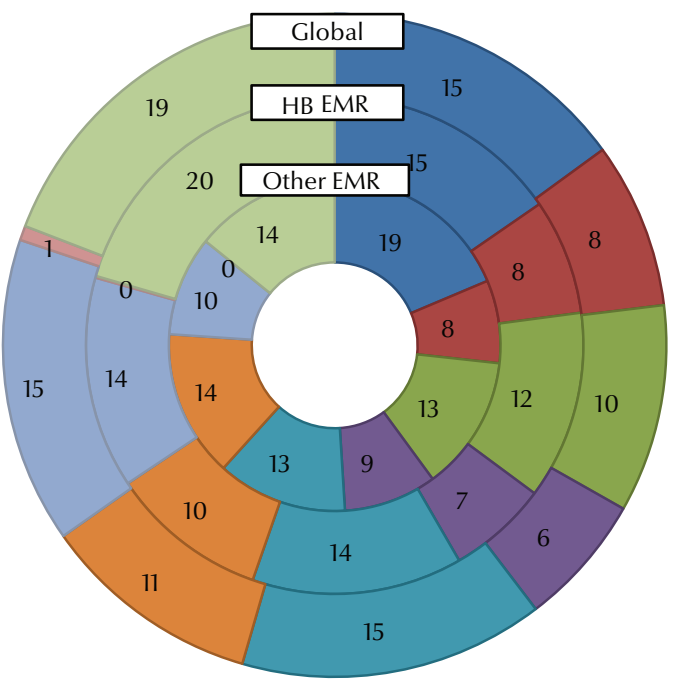

$\square$ Haemorrhage

$\square$ Sepsis and other maternal infections

$\square$ Hypertensive disorders

$\square$ Obstructed labour

$\square$ Abortive outcome

$\square$ Indirect maternal deaths

$\square$ Late maternal deaths

$\square$ HIV/AIDS

$\square$ Other maternal disorders

Figure 3 Cause of death (\%) for A) post-neonatal children (1-59 months) B) neonates ( $<1$ month) C) mothers (15-49 years) in priority and non-priority Eastern Mediterranean countries (HB EMR = high burden countries in the Eastern Mediterranean Region, other EMR = non-high burden countries in the Eastern Mediterranean Region) [Source: Child Health Epidemiology Reference Group (CHERG), 2014 (a,b); Institute for Health Metrics and Evaluation (c)] 
EMR countries $(\sim 20 \%)$ when compared with others $(\sim 10 \%)$. Neonatal infections accounted for another $17 \%$ and $13 \%$ of deaths in high-burden and non-high-burden countries respectively (Figure 3b).

\section{Maternal mortality ratios}

MMRs declined 50\% in the EMR between 1990 and 2013, from 340 to 170 maternal deaths per 100000 live births, which is similar to global (45\%) and developing region (47\%) reductions across the same time period (5). While substantial, the reduction is far from the MDG 5 target of a $75 \%$ reduction, and the Region's annual rate of reduction of $3.0 \%$ suggests that the EMR is not likely to reach its goal (5).

Two countries, Oman (77\% reduction) and Lebanon (75\% reduction), have already met their MDG 5 reduction target and the Islamic Republic of Iran is on-track (72\% reduction). Notwithstanding the evident gaps, many high-burden countries in the Region, including Pakistan, Afghanistan, Egypt, Syrian Arab Republic and Morocco, have decreased their MMRs around $60 \%$ or more, despite challenging contexts. Sudan, Palestine and Libya decreased MMR by approximately $50 \%$, and in the case of Sudan, the rate fell substantially from $720 \mathrm{ma}$ ternal deaths per 100000 live births in 1990 to 360 per 100000 in 2013. MMR in Tunisia, Djibouti, Jordan, Yemen, Iraq and Somalia dropped less than 50\% and these countries are unlikely to meet their targets (5). Many high-income countries have relatively low MMR ( $<25$ per 100000 births in 2013). However, Saudi Arabia and Qatar persisted in reducing their MMRs about 50\% from baseline figures, while Bahrain (5\% increase) and Kuwait (17\% increased) showed increased MMR over the time period.
Seven countries in the Region continue to have MMR > $100 \mathrm{ma}-$ ternal deaths per 100000 live births in 2013-Morocco (120), Pakistan (170), Djibouti (230), Yemen (270), Sudan (360), Afghanistan (400) and Somalia (850) — and approximately $80 \%$ of maternal deaths continue to occur in only 4 of these nations (Somalia, Afghanistan, Pakistan and Sudan). Together with Yemen, Morocco and Egypt, these high-burden countries accounted for nearly $95 \%$ of the 26000 maternal deaths in the Region in 2013 (5)

Maternal causes of death in the EMR mirror global trends, and are similar between high-burden and other EMR countries (Figure 3c). Pregnancy and delivery-related complications, such as haemorrhage, maternal infections, hypertensive disorders, obstructive labour and abortive outcomes, are the leading causes of maternal mortality, collectively accounting for about twothirds of all maternal deaths in 2013 (Figure 3c).

\section{Interventions coverage}

Estimates for $\mathrm{MNCH}$ interventions across the continuum of care are presented in Figure 4. The prevalence of contraceptive use is approximately $42 \%$ in the EMR, which is lower than the global average (64\%). Clear income differentials are apparent, as rates are considerably lower in lowincome countries (18\%).

Coverage of antenatal care is $93 \%$ for 1 visit and 60\% for $4+$ visits in the EMR. While coverage rates appear high overall, low-income countries in the Region have rates closer to $37 \%$ for 1 visit and $10 \%$ for $4+$ visits. The rates of skilled birth attendance follow a similar pattern and coverage in low-income countries is only $36 \%$ (compared with $96 \%$ in the EMR). Rates of antenatal care visits and skilled birth attendance are substantially higher in the EMR on average than global estimates.

Coverage of essential newborn and child vaccines (neonatal tetanus, 3-doses diphtheria-tetanus-pertussis, measles, 3-doses Haemophilus influenzae type B) is approximately $90 \%$ or higher in the EMR. However, in low-income countries coverage average around $50-60 \%$ and this increases with higher national income status.

Data on newborn-and child-feeding practices, care-seeking behaviour and use of treatments is only available for one-third of EMR countries (and is missing for all the high-income countries). Across available nations, the proportion of the mothers initiating breastfeeding within the first hour of birth averages about $42 \%$ and this is similar across income groups. Average coverage of exclusive breastfeeding within the first 5 months is $23 \%$, with evident gaps between the lower- and middle-income groups (ranging from 9-31\%). Income gaps are even are more pronounced for introduction of solid or semi-solid soft food (low-income countries average $16 \%$ coverage, while in upper-middle countries estimates reach 62\%); the EMR average is $51 \%$. Among children aged 0-59 months with symptoms of pneumonia, about $69 \%$ are taken to a skilled health provider, and $63 \%$ receive antibiotics for treatment. About 32\% of children aged 0-59 months with diarrhoea are treated with oral rehydration solutions, and 35\% have oral rehydration incorporated with continued feeding. Clear income differentials are apparent across the Region, with low-income countries having lower estimates on average.

\section{Social determinants of health}

\section{Poverty and food insecurity}

While the Gulf Cooperation Council states are some of the richest 

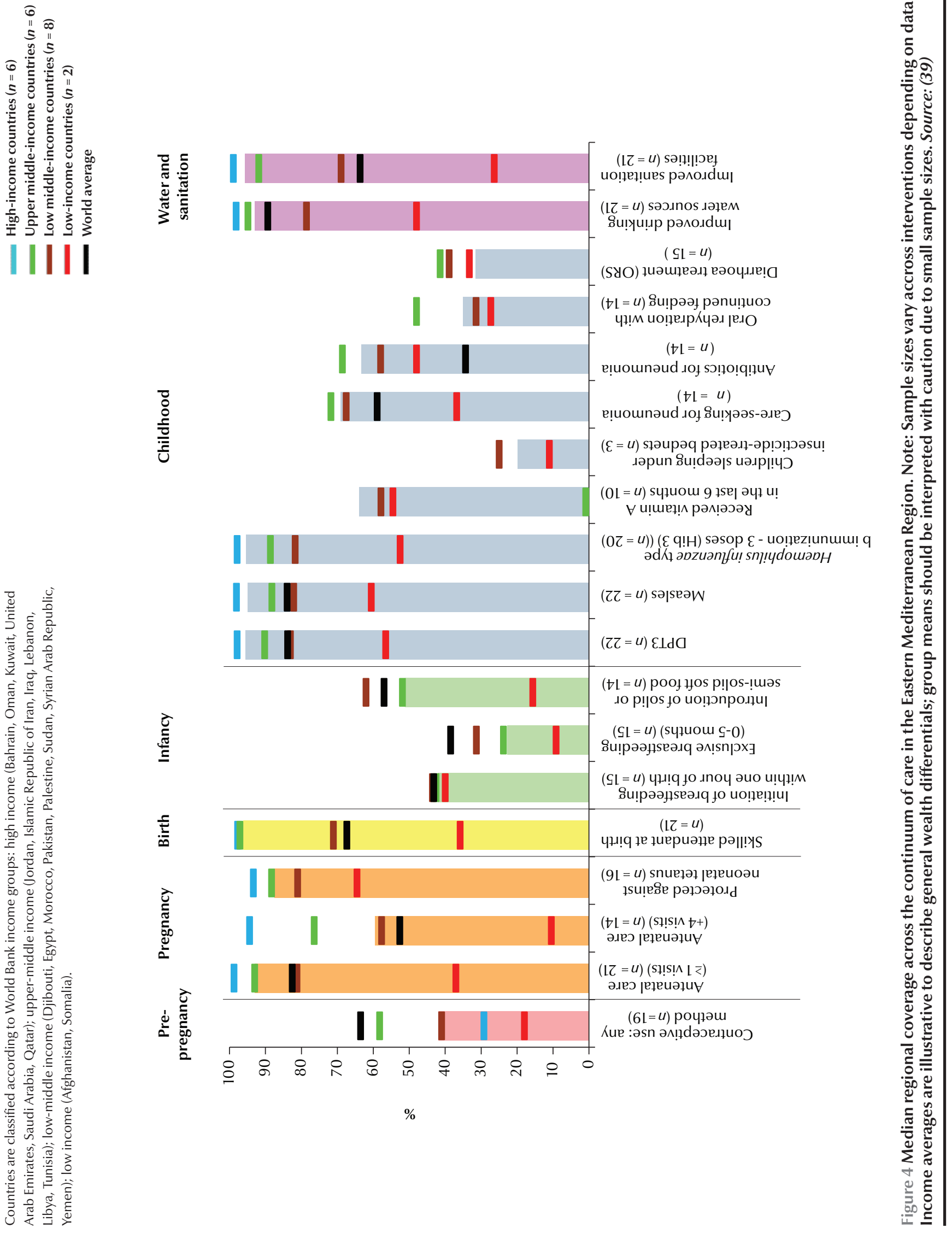
countries globally, poverty rates remain high in many other countries of the EMR. The proportion of the population living below the national poverty line is more than $20 \%$ in 7 EMR countries: Afghanistan (36\%), Egypt (22\%), Iraq (23\%), Pakistan (22\%), Palestine (22\%), Sudan (47\%) and Yemen (35\%) (12). In 5 of these countries, approximately one-third of the population is also food insecure: Afghanistan (34\%), Iraq (30\%), Pakistan (30\%), Sudan (33\%) and Yemen (36\%) (12).

\section{Malnutrition}

Stunting in children aged under 5 years old is highly prevalent in the EMR. The Region's average is comparable to global figures (approximately $24 \%$ stunted) (15). However, substantial disparities exist across the EMR (e.g. $32 \%$ versus 13\% stunted in high-burden versus non-highburden countries respectively). Four high-burden countries have under-5 stunting rates exceeding 40\% (Afghanistan, Pakistan, Somalia and Yemen), and 5 nations have rates < $10 \%$ (Kuwait, Islamic Republic of Iran, Jordan, Oman and Saudi Arabia). The best estimates of nutritional wasting indicate that Djibouti (22\%) and Sudan (16\%) have the highest rates in the Region, while the rates in most of the other countries range between 5-15\%. The EMR average rate of nutritional wasting is $8 \%$ and estimates are similar between highburden (10\%) and non-high-burden (7\%) groups.

In contrast, 3 countries in the Region-Libya (22\%), Syrian Arab Republic (18\%) and Lebanon (17\%) - have rates of overweight greater than $15 \%$, figures that characterize epidemics of rising public health concern. Across the Region, non-high-burden EMR countries have a higher prevalence of overweight on average $(11 \%)$ when compared with high-burden countries (7\%) (15).

\section{Water and sanitation}

Access of the population to improved drinking water sources is greater than $90 \%$ in the EMR, but estimates vary dramatically between countries. A clear gradient is evident across lowincome, low-middle, upper-middle and high-income countries (48\%, $79 \%, 95 \%$ and $98 \%$ respectively) (Figure 4).Likewise, the availability of improved sanitation facilities is high overall (94\%), but disaggregation by income reveals that low-income countries have approximately $26 \%$ access, while coverage in low-middle, upper-middle and high-income groups is $69 \%, 92 \%$ and $99 \%$ respectively.

\section{Conflict and population displace- ment}

Armed conflict and insecurity are ongoing concerns in the EMR. The best available data suggests that battle-related deaths have increased since the year 2000 in many nations. As of 2012, the total number of deaths related to battle (including civilians) were approximately 12127 (Sudan), 20412 (Somalia), 22532 (Pakistan), 25965 (Iraq) and over 50000 in Afghanistan (12). While data on civilian deaths, particularly among women and children, are not readily available, previous research suggests that up to $80 \%$ of these could be civilian deaths (18). In lieu of reliable data, the impact of current ongoing conflicts in Yemen, Syrian Arab Republic, Palestine and Libya are not well understood.

War and insecurity had also led to mass population displacement both internally and externally to nations. While exact figures are difficult to trace, hundreds of thousands to millions of civilians have been displaced internally in Afghanistan, Iraq, Pakistan, Somalia, Sudan, Syrian Arab
Republic, Libya, Palestine and Yemen in recent years (12). Countries neighbouring conflict-prone nations in the Region have also borne the brunt of the war with unexpected large-scale refugee population influx around war times. Over the past several years, the Islamic Republic of Iran, Pakistan, Jordan and Lebanon have hosted millions of refugees from bordering nations (12).

\section{Female empowerment}

Child marriage is highly prevalent in the EMR. Across 15 countries where recent data was available (excluding Gulf Cooperation Council nations), approximately one-quarter of all girls were married before the age of 18 years. In countries such as Afghanistan, Somalia, Sudan and Yemen the rate is around 50\% (12) and in Afghanistan and Yemen about $15 \%$ of girls are married as young adolescents before age 15 years.

The literacy rate among females older than 15 years is approximately $80 \%$ in the EMR on average, but varies across countries. On the lower end of the spectrum, the rate is around $67 \%$ for Morocco, 66\% for Yemen, $61 \%$ for Sudan, $55 \%$ for Pakistan and $32 \%$ for Afghanistan.

\section{Discussion and way forward}

\section{Results in context and effective interventions}

The EMR has made steady progress in improving maternal and child and survival. Nevertheless, with a $46 \%$ reduction in U5MR and a meagre $50 \%$ reduction in MMR, progress is lagging. Disparities within the Region are vast, with more than one-third of the countries off-track for MDG 4 targets. Four off-track countries contribute to the majority of under- 5 deaths in the Region (Somalia, 
Afghanistan, Pakistan and Sudan), and approximately 850000 children under 5 years old continue to die each year. Children in the EMR are dying largely from preventable infectious diseases, such as pneumonia and diarrhoea, for which cost-effective, evidence-based interventions are available (19). If implemented at scale, these interventions could prevent the majority of deaths from diarrhoea and more than two-thirds of those from pneumonia (19). Neonatal deaths account for $45 \%$ of all under-5 deaths in the Region and result mainly from basic obstetric complications, congenital anomalies and infections. These causes have been linked to maternal death and are highest among the poorest groups in the population (7).

Newborn health and survival has been largely neglected in the MDGs, however, and should be placed at the forefront of future efforts to improve child survival in the EMR. Nearly $80 \%$ of newborn mortality is preventable using cost-effective, evidence-based interventions, especially before, during and immediately after birth $(20,21)$. Annual deaths of over 26000 mothers in the Region due to complications such as excessive bleeding, high blood pressure/eclampsia, obstructive labour and infections can also be easily prevented.

Countries within the EMR should adapt and prioritize frameworks such as the Every Newborn Action Plan (20) and the Global Action Plan for Pneumonia and Diarrhoea (21) to safeguard optimal health and survival of the newborn, child and mother. Appropriate strategies and policies should be developed at the national and local levels, with strong stewardship and accountability mechanisms, and a specific focus on equity.

Improved and equitable access to $\mathrm{MNCH}$ interventions across the continuum of care have been related to decreased mortality (6). Equity analyses revealed that gaps in interventions coverage across the continuum of care often favour richer countries. Disparities are widest for contraceptive use, skilled attendance at delivery, care-seeking behaviour and treatment for pneumonia and diarrhoea, and access to improved water and sanitation facilities. Funding assistance and resource sharing/ channelling from higher to lower income countries is a vital step in reducing the glaring inequities in wealth across this Region.

Malnutrition is often exacerbated by illness and infectious diseases, food insecurity and poor food diversity and inadequate access to care. Overweight as well as undernutrition can adversely impact normal growth and development and has been linked to increased risk of morbidity and mortality. As a measure of chronic undernutrition, stunting is prevalent in more than $23 \%$ of children aged under 5 years in the EMR. Levels of its acute counterpart wasting, and overweight are prevalent in $8 \%$ and $9 \%$ respectively of children aged under 5 years in the EMR. This type of dual burden of nutrition problems places the EMR in a precarious predisposition for morbidity and mortality due to nutrition-related disorders. Greater emphasis should be placed on improving the nutritional status of children under 5 years old, particularly within the first 1000 days of life. Nutrition-specific and-sensitive interventions implemented in this period have been shown to have a high impact on improving health outcomes in childhood and adulthood, including better cognitive development, which ultimately contributes to improved human capital gains $(22,23)$.

Access to and utilization of family planning services has the potential to decrease population mortality rates by increasing birth spacing and decreasing the rate of high-risk pregnancies (24). There are cultural sensitivities, however, which may preclude women's access to reproductive education and services in many countries in the EMR and these barriers must be circumvented through information that engages and educates male household members. Female empowerment, assessed using indicators such as age at marriage and literacy, has been found to be associated with maternal and child health and survival (25-29). A younger age at marriage is associated with increased poverty, loss of education and widespread gender discrimination $(25,27)$. These in turn lead to high fertility and adverse fertility outcomes such as unwanted pregnancy and pregnancy termination (26), and increased risk of HIV/ AIDS (25), in tandem with poor socioeconomic status and inaccessibility of health services (30). Marriage in the adolescent years can increase the risk of maternal mortality and morbidity. Child marriage is prevalent in the EMR with nearly 50\% of girls getting married prior to 18 years of age in some high-burden priority countries and the literacy rates among females aged $>15$ years is also less than optimal across the Region. Female education promotes confidence, empowerment and increased use of health services (31). Thus, delaying the onset of marriage and first pregnancy and increasing female education must be emphasized in the Region as it promotes gender equity and female empowerment, and leads to improvement in overall maternal and child health (32).

Armed conflict in civilian areas results in mass displacement, replacing active battlefields with ill-equipped, unsanitary and overcrowded refugee camps (33). Environmental changes propelled by conflict and 
displacement result in food insecurity, lack of access to sanitation and health facilities, and inadequate care. Conflict can also facilitate to the breakdown of family structures, which can further exacerbate unhealthy environments and lead to the spread of disease, decreased food intake and nutrition, and eventually greater morbidity and mortality. The burden is most cumbersome on vulnerable groups such women and children. Conflict increases the incidence of sexual violence, not only to women but also to boys and girls. Higher rates of rape, sexually transmitted diseases, unwanted pregnancies and unsafe abortions have been documented in previous conflicts (34). The introduction of violence into the physical environment along with the collapse of normal societal and family structures further heightens the vulnerability of women and children (33). Conflict has been rampant in the EMR, and many countries continue to endure widespread insecurity and war. To mitigate the risks in war times and when facing humanitarian crises, particular attention must be paid to protecting the basic human rights of the vulnerable groups of the population and providing them with adequate shelter, food and access to care. While not diminishing the adverse psychological and social consequences on women and children, such protective measures can certainly maintain $\mathrm{MNCH}$ standards and improve survival.

\section{Actions taken and next steps in the EMR}

Recommendations from the Dubai Declaration in 2013, a high-level meeting on accelerating progress towards achieving MDGs 4 and 5 in the EMR (35), have resulted in maternal and child health acceleration plans for all high-burden countries in the EMR. Preliminary steps have been taken towards implementing maternal death surveillance and response systems, which are an active maternal death review process that identifies all maternal deaths and takes action to prevent future deaths. Progress has been made across all 9 high-burden countries: from advocating for support for maternal death surveillance and response systems at the national level, to strengthening the quality of existing systems (17). A WHO Regional Office for the Eastern Mediterranean intercountry meeting on care for children in the community in April 2014 also marked movement towards developing communitybased approaches for improved child care in high-burden countries in the Region (17). Results from the high-level joint planning meeting held by WHO, UNICEF, United Nations Population Fund and ministries of health in Amman in April 2015 regarding $\mathrm{MNCH}$ progress and country-specific prioritization/ targets into the sustainable development era are forthcoming.

While substantial progress has been made to improve women's and children's health in the EMR, further action is needed. Recommendations for the future of women's and children's health post-2015 have been created to implement a vigorous strategic and financial plan to help strengthen universal health. The aim is to do this by scaling up political and human rights commitments to women's and children's health. We summarize here the key guidelines set out by the independent Expert Review Group, in their most recent 2014 report and in previous reports, to accelerate progress in achieving optimal health and survival for women and children in the EMR (36-38) (Box 1). Since the initial independent Expert Review Group report in 2012, high-burden countries in the
EMR have made variable progress in adopting recommendations therein. Progress to date by country is highlighted in Appendices A and B. (available with the on line version).

\section{Conclusions}

Ministries of health, nongovernmental organizations and civic society across the EMR have, universally, identified reproductive, maternal and child health as a health priority, and have developed targeted national strategic plans to improve the health status of women and children. However, the EMR faces many unique health challenges such as demographic change, dual disease burden, rising health costs and the effects of ongoing conflict and population displacement. Many of these issues are exacerbated by the rise of instability due to political turmoil in the Region. Despite pervasive challenges, the EMR is a resourcerich region, uniting predominantly Muslim-majority nations, in a faith that promotes equity and social justice. Wide differentials in health outcomes and intervention coverage across income groups suggests that high-income countries in the Region should consider strategies for effectively channelling funds and vital resources to their lower-income counterparts. With a few months remaining to the target of the MDGs, the EMR must synergize efforts to reduce inequities and overcome bottlenecks. As the Region shifts into the post-2015 sustainable development era, the unfinished agenda of ending all preventable newborn, maternal and child deaths must remain central in order to accelerate progress and sustain the morbidity and mortality gains achieved in the EMR. 
Box 1 Recommendations from the independent Expert Review Group for accelerating progress in maternal and child health and survival. Source: Independent Expert Review Group on Information and Accountability for Women's and Children's Health, 2014 (38)

1. Strengthen the global governance framework for women's and children's health. Such plans will synergize efforts in interdisciplinary initiatives to ensure coordination and unity in implementing this governance gap.

2. Develop a global investment to take national investments and contributions into consideration to help guide a more targeted and strategic approach to women's and children's health.

3. Establish clear country-specific strategic priorities for implementing the Global Strategy for Women's, Children's and Adolescents' Health while also testing innovative mechanisms for delivering those priorities.

4. Accelerate the compliance and evaluation of eHealth and $\mathrm{mHealth}$ technologies. Assistance is advised by partners with the development and implementation of national eHealth plans, encouraging coordination between providers, and to support evaluation.

5. Strengthen human rights tools and frameworks to achieve better health and accountability for women and children. Human rights groups that address health are requested to include women and children into their work.

6. Expand the commitment and capacity to evaluate initiatives for women's and children's health. Evaluation is vital in addressing accountability, and partners are requested to establish a global research network to support the Global Strategy.

7. Strengthen country accountability. Ministers of health, with the help of partners, are asked to clearly prioritize and evaluate country-led, inclusive, transparent and participatory national oversight mechanisms to advance women's and children's health.

8. Demand global accountability for women and children. Promote and implement an independent accountability mechanism to monitor, review and continuously improve actions to deliver the post-2015 sustainable development agenda.

9. Take adolescents seriously. Comprise an adolescent indicator in all monitoring mechanisms for women's and children's health, and involve young people on all policy-making bodies affecting women and children in a meaningful manner.

10. Prioritize quality to reinforce the value of a human-rights-based approaches to women's and children's health. Quality of care should be the path to equity and dignity for women and children.

11. Make health professionals count. Deliver an expanded and skilled health workforce, which serves women and children with measureable impact.

12. Launch a new movement for better data. Make universal and effective civil registration and vital statistics systems a target post-2015.

13. Develop, secure wide political support for and begin to implement a global plan during 2014-2015 to end all preventable reproductive, maternal, newborn, child and adolescent mortality for the period 2016-2030: a more inclusive Global Strategy for Women's and Children's health. Long-term strategies that focus on important needs for women and children are needed instead of waiting for governments to agree on Sustainable Development Goals. These needs include: to accelerate the delivery of life-saving interventions such as vaccines to women and children; to focus on the sexual and reproductive health, rights and well-being of the adolescent girl, delivering universal health coverage now; to protect health by investing in education for girls; and to address the unmet need for safe abortion practices. The post-2015 Global Strategy requires attention to the multisectoral nature of women's and children's health, not solely health-sector investments but also non-health-sector investments.

14. In 2015, devise a results-based financing facility to support and sustain this new Global Strategy. An investment framework for predictable performance-based financing systems, both globally and domestically, has been established but not fully implemented. Involvement of funders is necessary for the investment framework to be fully active. The independent Expert Review Group recommends that those involved in reproductive, maternal, newborn and child health join together with other partners such as nongovernmental organizations and donors to generate long-term investments to improve women and children's health.

\section{References}

1. Resolution 55/2. United Nations Millennium Declaration. In: Fifty-fifth session of the General Assembly, New York, 18 September 2000. New York (NY): United Nations; 2000 (http:// www.un.org/millennium/declaration/ares552e.pdf, accessed 10 July 2015).
2. The Millennium Development Goals report 2012. New York (NY): United Nations; 2012.

3. Levels and trends in child mortality. Estimates developed by the UN Inter-agency Group for Child Mortality Estimation. Report 2014. Geneva: United Nations Children's Fund; 2014 (http:// 
www.data.unicef.org/fckimages/uploads/1410869227 Child_Mortality_Report_2014.pdf, accessed 10 July 2015).

4. Wang $\mathrm{H}$, Liddell CA, Coates MM, Mooney MD, Levitz $\mathrm{CE}$, Schumacher AE, et al. Global, regional, and national levels of neonatal, infant, and under-5 mortality during 1990-2013: a systematic analysis for the Global Burden of Disease Study 2013. Lancet. 2014 Sep 13;384(9947):957-79. PMID:24797572

5. Trends in maternal mortality: 1990-2013. Geneva: World Health Organization, United Nations Children's Fund, UNFPA, the World Bank and the United Nations Population Division; 2014.

6. Countdown to 2015. Fulfilling the health agenda for women and children: the 2014 report. Geneva: World Health Organization and United Nations Children's Fund; 2014.

7. Liu L, Oza S, Hogan D, Perin J, Rudan I, Lawn JE, et al. Child Health Epidemiology Reference Group (CHERG), Global, regional, and national causes of child mortality in 2000-13, with projections to inform post-2015 priorities: an updated systematic analysis. Lancet. 2014; 385(9966):430-40. PMID:25280870

8. Shaping the future of health in the WHO Eastern Mediterranean Region: Reinforcing the role of WHO. Cairo: World Health Organization, Regional Office for the Eastern Mediterranean; 2012 (http://applications.emro.who.int/dsaf/ EMROPUB_2012_EN_742.pdf, accessed 10 July 2015).

9. Bhutta ZA, Belgaumi A, Abdur Rab M, Karrar Z, Khashaba $M$, Mouane N. Child health and survival in the Eastern Mediterranean region. BMJ. 2006 Oct 21;333(7573):839-42. PMID:17053238

10. Bhutta ZA. Child mortality in the Eastern Mediterranean Region: challenges and opportunities. East Mediterr Health J. 2013 Feb;19(2):104-6. PMID:23516817

11. Global health observatory data repository. Geneva: World Health Organization; 2014.

12. World DataBank [Internet]. Washington (DC): World Bank; 2014 (http://databank.worldbank.org/data/home.aspx, accessed 10 July 2015).

13. UNICEF data: monitoring the situation of children and women [Internet]. Geneva: United Nations' Children's Fund; 2014 (http://data.unicef.org/, accessed 10 July 2015).

14. Data and estimates [Internet]. Geneva: WHO/UNICEF Joint Monitoring Programme (JMP) for Water Supply and Sanitation World Health Organization and UNICEF; 2014 (http:// www.wssinfo.org/data-estimates/, accessed 10 July 2015).

15. Joint child malnutrition estimates (UNICEF/WHO/World Bank) [Internet]. Washington (DC): World Bank; 2014 (http://data.worldbank.org/child-malnutrition, accessed 12 January 2015).

16. Updated income classifications. Washington (DC): World Bank; 2014 (http://data.worldbank.org/news/2015-country-classifications, accessed 10 July 2015).

17. WHO events addressing public health priorities. East Mediterr Health J. 2014 Oct;20(10):667-9. PMID:25356700

18. Bhutta ZA, Yousafzai AK, Zipursky A. Pediatrics, war, and children. Curr Probl Pediatr Adolesc Health Care. 2010 Feb;40(2):20-35. PMID:20152786

19. Bhutta ZA, Das JK, Walker N, Rizvi A, Campbell H, Rudan I, et al.; Lancet Diarrhoea and Pneumonia Interventions Study Group. Interventions to address deaths from childhood pneumonia and diarrhoea equitably: what works and at what cost? Lancet. 2013 Apr 20;381(9875):1417-29. 10.1016/ S0140-6736(13)60648-0 PMID:23582723

20. Every newborn: An action plan to end preventable deaths. Geneva, World Health Organization, 2014 (http://www. who.int/maternal_child_adolescent/topics/newborn/ enap_consultation/en/, accessed 10 July 2015).

21. Ending preventable child deaths from pneumonia and diarrhoea by 2025: the integrated Global Action Plan for Pneumonia and Diarrhoea (GAPPD). Geneva: World Health Organization and United Nations Children's Fund; 2013.

22. Lawn JE, Blencowe H, Oza S, You D, Lee AC, Waiswa P, et al.; Lancet Every Newborn Study Group. Every Newborn: progress, priorities, and potential beyond survival. Lancet. 2014 Jul 12;384(9938):189-205. PMID:24853593

23. Black RE, Victora CG, Walker SP, Bhutta ZA, Christian P, de Onis $M$, et al.; Maternal and Child Nutrition Study Group. Maternal and child undernutrition and overweight in lowincome and middle-income countries. Lancet. 2013 Aug 3;382(9890):427-51. PMID:23746772

24. Victora CG, Adair L, Fall C, Hallal PC, Martorell R, Richter L, et al.; Maternal and Child Undernutrition Study Group. Maternal and child undernutrition: consequences for adult health and human capital. Lancet. 2008 Jan 26;371(9609):340-57. PMID:18206223

25. Bhutta ZA, Das JK, Bahl R, Lawn JE, Salam RA, Paul VK, et al.; Lancet Newborn Interventions Review Group; Lancet Every Newborn Study Group. Can available interventions end preventable deaths in mothers, newborn babies, and stillbirths, and at what cost? Lancet. 2014 Jul 26;384(9940):347-70. PMID:24853604

26. Grown C, Gupta GR, Pande R. Taking action to improve women's health through gender equality and women's empowerment. Lancet. 2005 Feb 5-11;365(9458):541-3. PMID:15705464

27. Nasrullah M, Muazzam S, Bhutta ZA, Raj A. Girl child marriage and its effect on fertility in Pakistan: findings from Pakistan Demographic and Health Survey, 2006-2007. Matern Child Health J. 2014 Apr;18(3):534-43. PMID:23580067

28. New insights on preventing child marriage: a global analysis of factors and programmes. Washington (DC): International Council for Research on Women; 2007 (https://www.icrw. org/files/publications/New-Insights-on-Preventing-ChildMarriage.pdf, accessed 10 July 2015).

29. Early marriage: a harmful traditional practice. Geneva: United Nations Children's Fund; 2005. (http://www.unicef. org/publications/files/Early_ Marriage_12.lo.pdf, accessed 10 July 2015).

30. Sathar ZA, UI Haque M, Faizunnissa A, Sultana M, Lloyd CB, Diers JA, et al. Adolescents and youth in Pakistan 2001-2002: A nationally representative survey. Islamabad: UNICEF and Population Council; 2002.

31. Bhatia JC, Cleland J. Determinants of maternal care in a region of South India. Health Transit Rev. 1995 Oct; 5(2):12742.

32. 32. Bhutta ZA, Chopra M, Axelson H, Berman P, Boerma T, Bryce J, et al. Countdown to 2015 decade report (2000-10): taking stock of maternal, newborn, and child survival. Lancet. 2010 Jun 5;375(9730):2032-44. PMID:20569843

33. Machel Study 10-year strategic review. Children and conflict in a changing world. Geneva: United Nations Children's Fund; 2009 .

34. Cottingham J, García-Moreno C, Reis C. Sexual and reproductive health in conflict areas: the imperative to address violence against women. BJOG. 2008 Feb;115(3):301-3. PMID:18190365

35. Saving the lives of mothers and children: rising to the challenge. Background document for the High Level Meeting on Saving the Lives of Mothers and Children: Accelerating Progress Towards Achieving MDGs 4 and 5 in the Region, Dubai, United Arab Emirates, 29-30 January 2013. Cairo: 
World Health Organization, Regional Office for the Eastern Mediterranean (http://applications.emro. who.int/docs/ High_Level_Exp_Reg_doc_2013_EN_14811.pdf, accessed 10 July 2015).

36. Every woman, every child: from commitments to action: the first report of the independent Expert Review Group (iERG) on Information and Accountability for Women's and Children's Health. Geneva: World Health Organization; 2012.

37. Every woman, every child: strengthening equity and dignity through health: the second report of the independent Expert Review Group (iERG) on Information and Accountability for Women's and Children's Health. Geneva: World Health Organization; 2013.
38. Every woman, every child: a post-2015 vision: the third report of the independent Expert Review Group on Information and Accountability for Women's and Children's Health. Geneva: World Health Organization; 2014 (http://apps. who.int/iris/bitstream/10665/132673/1/9789241507523 eng.pdf, accessed 10 July 2015).

39. Every child counts. The state of the world's children in numbers. Revealing disparities, advancing children's rights, New York (NY): United Nations Children's Fund; 2014 (http:// www.unicef.org/gambia/SOWC_report_2014.pdf accessed 10 July 2015). 